\title{
Benefit of Glycemic Control for Reducing the Effects of Air Pollution on Blood Pressure: A Panel Study
}

Youn-Hee Lim ${ }^{1}$, Ho Kim², Jin Hee Kim ${ }^{3}$, Sanghyuk Bae ${ }^{4}$, Hye Yin Park ${ }^{5}$, Hyun Joo Bae ${ }^{6}$, Hee Lak Choi ${ }^{7}$ and Yun-Chul Hong ${ }^{3,8^{*}}$

${ }^{1}$ Institute of Health and Environment, Graduate School of Public Health, Seoul National University, Seoul, Republic of Korea

${ }^{2}$ Department of Epidemiology and Biostatistics, Graduate School of Public Health, Seoul National University, Seoul, Republic of Korea

${ }^{3}$ Institute of Environmental Medicine, Seoul National University Medical Research Center, Seoul, Republic of Korea

${ }^{4}$ Environmental Health Center, Seoul National University College of Medicine, Seoul, Republic of Korea

${ }^{5}$ Department of Preventive Medicine, Seoul National University College of Medicine, Seoul, Republic of Korea

${ }^{6}$ Korea Environment Institute, Seoul, Republic of Korea

${ }^{7}$ National Institute of Environmental Research, Incheon, Republic of Korea

${ }^{8}$ Institute of Medical Research, Seoul National University Bundang Hospital, Seongnam, Republic of Korea

\begin{abstract}
Objective: Diabetes mellitus (DM) is known to aggravate the association between air pollution and cardiovascular diseases, such as hypertension. However, the influence may differ based on the degree of glycemic control. Therefore, we hypothesized that the adverse effects of air pollutants on Blood Pressure (BP) in patients with controlled DM would be less than those in patients with uncontrolled DM.

Methods: Data were analyzed from a panel study of 560 elderly participants, conducted between 2008 and 2010 in Seoul, Korea. Mixed effects models were used to assess the association of air pollutants [particulate matter with aerodynamic diameters $<10 \mu \mathrm{m}\left(\mathrm{PM}_{10}\right), \mathrm{PM}_{2.5}, \mathrm{PM}_{10-2.5}$, nitrogen dioxide, ozone, sulfur dioxide, and carbon monoxide] with BP. We compared the magnitude of the effects among individuals with controlled and uncontrolled DM and those without DM.

Results: Increases in the interquartile range levels of $\mathrm{PM}_{10}$ were significantly associated with $2.0 \mathrm{mmHg}(95 \%$ $\mathrm{Cl}, 0.7-41.7 \mathrm{mmHg}$ ) increases in systolic BP (SBP) and $2.0 \mathrm{mmHg}(95 \% \mathrm{Cl}, 1.2-41.7 \mathrm{mmHg})$ increases in diastolic BP (DBP) when we analyzed all participants. Most of the other air pollutants, except ozone, were also associated with significant increases in BP. When we compared the BP changes among the three groups (non-DM, controlled DM, and uncontrolled DM), significant increases in SBP and DBP were observed in participants with uncontrolled DM and those without DM; significant BP increases were not observed in participants with controlled DM.
\end{abstract}

Conclusion: Glycemic control provided benefits for alleviating BP changes associated with exposure to air pollutants.

Keywords: Air pollution; Blood pressure; Diabetes mellitus; Elderly; Glycemic control; Inflammation; Mixed effects model; Panel study

\section{Introduction}

Air pollution is known to affect the markers of cardiovascular health, such as Blood Pressure (BP), heart rate variability, inflammation, and coagulation [1-3]. Plausible pathways for the association between cardiovascular disease and air pollution are speculated to involve oxidative stress, inflammation, elevated endothelin activity, or altered autonomic nervous system balance [4,5]. Because cardiovascular diseases and Diabetes Mellitus (DM) share common pathways, such as oxidative stress and inflammation, there is a possibility that the association between cardiovascular health indicators and air pollution is modified by an individual's DM status. Studies have found that markers of systemic inflammation, impaired vascular reactivity, and cardiovascular events are affected more by air pollution among individuals with DM than among others [6-9]. However, controlled and uncontrolled DM may have different effects on cardiovascular symptoms or diseases because glycemic control reduces not only glucose levels but may also reduce inflammation and oxidative stress. In fact, the use of anti-diabetic medications has been suggested to reduce cardiovascular disease events [10]. Hence, good glycemic control may result in fewer or less severe adverse cardiovascular effects, upon exposure to air pollutants, compared to uncontrolled DM.

In this study, we used systolic and diastolic BP (SBP and DBP, respectively) as markers of cardiovascular health because $\mathrm{BP}$ has been previously reported to be affected by the exposure to air pollutants [1115]. We hypothesized that the adverse effects of air pollutants on SBP and DBP would be less in patients with controlled DM than in those with uncontrolled DM or, possibly, in non-DM individuals.

\section{Materials and Methods}

\section{Population}

This study evaluated data from a study of 560 elderly participants who regularly visited a community welfare center, located in the midnorthern part of Seoul, Korea, between 2008 and 2010. During the 3-year study period, 179 participants visited the welfare center only once, 196 visited twice, and 182 visited three times. We obtained

*Corresponding author: Yun-Chul Hong, Institute of Environmental Medicine, Seoul National University Medical Research Center, 103 Daehakro, Jongro-gu, Seoul 110-799, Republic of Korea, Tel: +82-2-740-8394; Fax: +82-2-747-4830 E-mail: ychong1@snu.ac.kr

Received June 27, 2014; Accepted September 16, 2014; Published September 24, 2014

Citation: Lim YH, Kim H, Kim JH, Bae S, Park HY, et al. (2014) Benefit of Glycemic Control for Reducing the Effects of Air Pollution on Blood Pressure: A Panel Study. J Diabetes Metab 5: 434 doi:10.4172/2155-6156.1000434

Copyright: ( $2014 \mathrm{Lim} \mathrm{YH}$, et al. This is an open-access article distributed under the terms of the Creative Commons Attribution License, which permits unrestricted use, distribution, and reproduction in any medium, provided the original author and source are credited. 
written informed consent from all participants and the Institutional Review Board (IRB) of Seoul National University Hospital reviewed and approved the study protocol (IRB no. H-0804-045-241).

We performed the first round of this 3-year study between August and December 2008, the second between April and October 2009, and the last between March and August 2010. From the baseline questionnaires administered by interviewers, we recorded each patient's demographic and behavioral characteristics, a self-reported history of doctor-diagnosed chronic diseases, including DM, and data on whether medications were used within the past year (yes or no). At each visit, the participants underwent physical examinations, and fasting blood and urine samples were drawn between 0900 and $1200 \mathrm{~h}$ on the same day. Individuals with missing information regarding their DM status or measurements of fasting glucose were excluded $(n=3)$.

\section{Blood pressure and diabetes mellitus}

BP was measured by trained medical technologists, using an automatic sphygmomanometer (HEM-780; Omron, Kyoto, Japan) after the participant had rested for more than 10-min. Participants were asked to remain in a sedentary for an additional 10 minutes, prior to a second blood pressure measurement being conducted. The mean SBP and DBP were calculated from the 2 measurements, and used as the dependent variable in the analyses.

Responses to the baseline questionnaire regarding doctordiagnosed diabetes and measured serum glucose levels, determined using the hexokinase method (Pureauto S GLU kit, Daiichi Pure Chemicals, Tokyo, Japan), were used to define non-DM, controlled DM, and uncontrolled DM participants. DM was defined at each visit when the participant was diagnosed with diabetes (regardless of treatment) or when the participant had a fasting serum glucose level $(\mathrm{FG}) \geq 126 \mathrm{mg} / \mathrm{dL}$ at the visit. Among participants with $\mathrm{DM}$, we stratified the individuals into 2 groups: the uncontrolled (FG $\geq 110 \mathrm{mg} /$ $\mathrm{dL})$ and the controlled (FG<110 mg/dL) DM groups. The cutoff points were determined using the World Health Organization guidelines for diabetes $(126 \mathrm{mg} / \mathrm{dL})$ and impaired fasting glucose $(110 \mathrm{mg} / \mathrm{dL})$ [16].

\section{Environmental variables}

We computed the daily air pollution concentrations (particulate matter with aerodynamic diameters less than $10 \mu \mathrm{m}\left(\mathrm{PM}_{10}\right), \mathrm{PM}_{25}$, $\mathrm{PM}_{10-2.5}$, nitrogen dioxide $\left(\mathrm{NO}_{2}\right)$, ozone $\left(\mathrm{O}_{3}\right)$, sulfur dioxide $\left(\mathrm{SO}_{2}\right)$, and carbon monoxide $(\mathrm{CO})$ ) by averaging the 24 -h data obtained from the Research Institute of Public Health and Environment (Seoul, Korea). These particles and gaseous pollutants were measured from the rooftops of municipal buildings in Seongbuk-Gu throughout the study period (August 2008-August 2010). Detailed information regarding the measurement methods were described previously [17]. We also collected data on the temperature $\left({ }^{\circ} \mathrm{C}\right)$, sea-level pressure $(\mathrm{hPa})$, and humidity (\%) from the Korea Meteorological Administration to adjust for other environmental confounders.

\section{Statistical analyses}

We used mixed effect models with a compound symmetry covariance structure to assess the association of air pollution with SBP and DBP in order to account for inter- and intra-subject variability. The confounding variables considered were age (years), gender (male or female), exercise (less than once a week or more), regular alcohol consumption (yes or no), body mass index (BMI, $\mathrm{kg} / \mathrm{m}^{2}$ ), history of hypertension (yes or no), cotinine level ( $\mu \mathrm{g} / \mathrm{g}$ creatinine) as a proxy of exposure to either passive or active smoking, education (more or less than or equal to 6 years of schooling), number of visits for study participation (1-3 times), daily mean temperature $\left({ }^{\circ} \mathrm{C}\right)$, relative humidity (\%), sea-level pressure $(\mathrm{hPa})$, and season (spring, summer, fall, or winter).

We analyzed SBP and DBP changes related to the air pollutants $\left(\mathrm{PM}_{10}, \mathrm{PM}_{2.5}, \mathrm{PM}_{10-2.5}, \mathrm{PM}, \mathrm{NO}_{2}, \mathrm{O}_{3}, \mathrm{SO}_{2}\right.$, and $\left.\mathrm{CO}\right)$. To examine lagged effects of air pollutants, we computed the moving average of air pollutants from the concurrent day to 6 days previously, and analyzed the association of lagged pollutant changes with BP. We compared the magnitude of the air pollution effects on BP changes by subgroups (non-DM, controlled DM, and uncontrolled DM). Effects were shown as changes in SBP and DBP per Interquartile Range (IQR) increases of ambient pollutants with 95\% Confidence Intervals (CI).

To reduce selection bias of non-random missing data, we considered follow-up weighting, as described in detail in our previous study $[17,18]$. Briefly, we calculated the inverse probability of attaining a follow-up response from logistic regression using the previous measurements, including age, sex, BMI, number of years of schooling, blood pressure, season, and temperature [19]. A weighting of 1 was given to the first observation for each participant and greater weighting (the inverse of predicted probability of having a follow-up response) to the observations that were more likely missing [20]. All statistical analyses were conducted using SAS software (Version 9.3, SAS Institute, Cary, NC, USA).

\section{Results}

At the first visit, involving 557 participants, 101 individuals were classified as having DM, based on the self-reported results and the measured glucose levels. Of the $101 \mathrm{DM}$ participants, more than half $(n=54)$ had uncontrolled DM (FG $\geq 110 \mathrm{mg} / \mathrm{dL})$. The mean age of the participants at the first visit was 70.7 years; $74 \%$ were female. Glucose levels were higher among individuals in the DM group $(120.3 \mathrm{mg} / \mathrm{dL})$ than among those in the non-DM group $(91.0 \mathrm{mg} / \mathrm{dL})$. Among the DM participants, the uncontrolled group had a higher mean glucose level $(140.8 \mathrm{mg} / \mathrm{dL})$ than did the controlled group $(95.3 \mathrm{mg} / \mathrm{dL})$ (Table 1$)$.

The average temperature during the study period (2008-2010) was $17.4^{\circ} \mathrm{C}$ (standard deviation (SD) $8.1^{\circ} \mathrm{C}$ ); temperatures on the days when the participants with controlled DM visited the center $\left(19.4^{\circ} \mathrm{C}\right.$ $\left(7.0^{\circ} \mathrm{C}\right)$ ) were higher than when those with uncontrolled DM visited $\left(17.0^{\circ} \mathrm{C}\left(8.2^{\circ} \mathrm{C}\right)\right)$. The average air pollutant concentrations during the study period were $41.6(15.5) \mu \mathrm{g} / \mathrm{m}^{3}$ for $\mathrm{PM}_{10}, 22.3(7.6) \mu \mathrm{g} / \mathrm{m}^{3}$ for $\mathrm{PM}_{2.5}$, $19.3(9.6) \mu \mathrm{g} / \mathrm{m}^{3}$ for $\mathrm{PM}_{10-2.5}, 35.7$ (7.4) ppb for $\mathrm{NO}_{2}, 30.6$ (11.2) ppb for $\mathrm{O}_{3}, 3.8$ (1.5) ppb for $\mathrm{SO}_{2}$, and 0.57 (0.17) ppm for CO. Air pollution concentrations, except for $\mathrm{O}_{3}$, were significantly higher on the days when the uncontrolled DM participants visited the center than when the controlled DM participants visited (P-value<0.05) (Table 2). Of the three examination times, the mean outdoor temperature was higher at the second visit $\left(22.0^{\circ} \mathrm{C}\right)$ than at the first $\left(15.4^{\circ} \mathrm{C}\right)$ or third $\left(14.9^{\circ} \mathrm{C}\right)$ visits. The ambient pollutant concentrations $\left(\mathrm{PM}_{10}, \mathrm{PM}_{2.5}, \mathrm{PM}_{10-2.5}, \mathrm{NO}_{2}\right.$, $\mathrm{O}_{3}, \mathrm{SO}_{2}$, and $\mathrm{CO}$ ) were higher at the first and third visits than at the second visit (Supplementary Material, Table S1).

When we analyzed all participants, increases in the $\mathrm{PM}_{10} \mathrm{IQR}$ levels were associated with $2.0 \mathrm{mmHg}$ ( $95 \% \mathrm{CI}, 0.7-41.7 \mathrm{mmHg}$ ) increases in SBP and $2.0 \mathrm{mmHg}(95 \% \mathrm{CI}, 1.2-41.7 \mathrm{mmHg}$ ) increases in DBP (Table 3). Increased $\mathrm{PM}_{2.5}$ levels were associated with SBP increases of $1.4 \mathrm{mmHg}$ (95\% CI, 0.3-18.9 mmHg) and DBP increases of $1.4 \mathrm{mmHg}$ (95\% CI, 0.8-18.9 mm Hg). Coarse particles, $\mathrm{PM}_{10-2.5}$, showed greater SBP (2.5 mmHg (95\% CI, 0.8-26.9 mmHg)) and DBP (2.3 mmHg (95\% 
Citation: Lim YH, Kim H, Kim JH, Bae S, Park HY, et al. (2014) Benefit of Glycemic Control for Reducing the Effects of Air Pollution on Blood Pressure: A Panel Study. J Diabetes Metab 5: 434 doi:10.4172/2155-6156.1000434

Page 3 of 6

\begin{tabular}{|c|c|c|c|c|c|}
\hline & \multicolumn{5}{|c|}{ Mean \pm Standard deviation, $N(\%)$} \\
\hline & \multirow{2}{*}{ Total $(\mathrm{N}=557)$} & \multirow{2}{*}{ Non-DM ( $\mathrm{N}=456)$} & \multicolumn{3}{|c|}{ DM } \\
\hline & & & Total $(\mathrm{N}=101)$ & Controlled $(\mathrm{N}=47)$ & Uncontrolled $(\mathrm{N}=54)$ \\
\hline Age, years & $70.7 \pm 5.3$ & $70.6 \pm 5.3$ & $71.1 \pm 5.1$ & $70.7 \pm 4.2$ & $71.3 \pm 5.7$ \\
\hline Glucose, mg/dL & $96.2 \pm 20.4$ & $91.0 \pm 10.6$ & $120.3 \pm 33.5^{\star}$ & $95.3 \pm 9.5$ & $140.8 \pm 32.1^{*}$ \\
\hline $\mathrm{SBP}, \mathrm{mmHg}$ & $131.8 \pm 16.7$ & $131.8 \pm 16.7$ & $131.6 \pm 17.0$ & $130.5 \pm 16.6$ & $132.5 \pm 17.5$ \\
\hline $\mathrm{DBP}, \mathrm{mmHg}$ & $74.5 \pm 9.9$ & $74.9 \pm 9.9$ & $72.7 \pm 10.0^{*}$ & $72.5 \pm 9.2$ & $73.0 \pm 10.7$ \\
\hline \multicolumn{6}{|l|}{ Sex } \\
\hline Male & $144(25.9 \%)$ & $116(25.4 \%)$ & $28(27.7 \%)$ & $16(34.0 \%)$ & $12(22.2 \%)$ \\
\hline Female & $413(74.1 \%)$ & $340(74.6 \%)$ & $73(72.3 \%)$ & $31(66.0 \%)$ & $42(77.8 \%)$ \\
\hline \multicolumn{6}{|l|}{$\mathrm{BMl}^{\mathrm{a}}$} \\
\hline$<$ Q1 & $139(25.0 \%)$ & $120(26.3 \%)$ & $19(18.8 \%)$ & $10(21.3 \%)$ & $9(16.7 \%)$ \\
\hline Q1-Q3 & $284(51.0 \%)$ & $233(51.1 \%)$ & $51(50.5 \%)$ & $19(40.4 \%)$ & $32(59.3 \%)$ \\
\hline$\geq$ Q3 & $134(24.1 \%)$ & $103(22.6 \%)$ & $31(30.7 \%)$ & $18(38.3 \%)$ & $13(24.1 \%)$ \\
\hline \multicolumn{6}{|l|}{ Exercise } \\
\hline Yes & $343(63.2 \%)$ & $274(61.9 \%)$ & $69(69.0 \%)$ & $35(74.5 \%)$ & $34(64.2 \%)$ \\
\hline No & $200(36.8 \%)$ & $169(38.1 \%)$ & $31(31.0 \%)$ & $12(25.5 \%)$ & $19(35.8 \%)$ \\
\hline \multicolumn{6}{|c|}{ Alcohol consumption } \\
\hline Yes & $121(22.4 \%)$ & $96(21.8 \%)$ & $25(25.3 \%)$ & $12(25.5 \%)$ & $13(25.0 \%)$ \\
\hline No & $419(77.6 \%)$ & $345(78.2 \%)$ & $74(74.7 \%)$ & $35(74.5 \%)$ & $39(75.0 \%)$ \\
\hline \multicolumn{6}{|l|}{$\begin{array}{l}\text { Cotinine Level } \\
\text { ( } \mu \mathrm{g} / \mathrm{g} \text { creatinine) }\end{array}$} \\
\hline$>400$ & $31(5.6 \%)$ & $27(6.0 \%)$ & $4(4.0 \%)$ & $2(4.3 \%)$ & $2(3.7 \%)$ \\
\hline$\leq 400$ & $518(94.4 \%)$ & $422(94.0 \%)$ & $96(96.0 \%)$ & $44(95.7 \%)$ & $52(96.3 \%)$ \\
\hline \multicolumn{6}{|l|}{ Education years } \\
\hline$<6$ years & $171(30.7 \%)$ & $136(29.8 \%)$ & $35(34.7 \%)$ & $15(31.9 \%)$ & $20(37.0 \%)$ \\
\hline$\geq 6$ years & $386(69.3 \%)$ & $320(70.2 \%)$ & $66(65.3 \%)$ & $32(68.1 \%)$ & $34(63.0 \%)$ \\
\hline \multicolumn{6}{|l|}{ Hypertension } \\
\hline Yes & $279(50.1 \%)$ & $216(47.4 \%)$ & $63(62.4 \%)^{*}$ & $28(59.6 \%)$ & $35(64.8 \%)$ \\
\hline No & $278(49.9 \%)$ & $240(52.6 \%)$ & $38(37.6 \%)$ & $19(40.4 \%)$ & $19(35.2 \%)$ \\
\hline
\end{tabular}

Abbreviations: DM: participants diagnosed as diabetes (under treatment or no treatment), or having fasting serum glucose level (FG) $\geq 126 \mathrm{mg} / \mathrm{dL}$ ( $7.0 \mathrm{mmol} / \mathrm{L}$ ) at a visit; non-DM, otherwise; Uncontrolled DM, FG $\geq 110 \mathrm{mg} / \mathrm{dL}$; controlled DM (FG $\leq 110 \mathrm{mg} / \mathrm{dL}$ ) among DM participants; SBP: Systolic Blood Pressure; DBP: Diastolic Blood Pressure

Significant difference (P-value<0.05) between non-DM and DM group (marked on total DM) or between uncontrolled and controlled DM group (marked on uncontrolled DM).

${ }^{\mathrm{a}}$ Quartile values of Body Mass Index (BMI) levels $\left(\mathrm{kg} / \mathrm{m}^{2}\right)$ : $\mathrm{Q} 1=23$ and $\mathrm{Q} 3=27$.

Table 1: Baseline Characteristics of the Participants by state of Diabetes Mellitus (DM).

\begin{tabular}{|c|c|c|c|c|c|}
\hline \multirow{3}{*}{ Environmental variables } & \multicolumn{5}{|c|}{ Mean (Standard Deviation) } \\
\hline & \multirow{2}{*}{ Total } & \multirow{2}{*}{ Non-DM } & \multicolumn{3}{|c|}{ DM } \\
\hline & & & Total & Controlled & Uncontrolled \\
\hline \multicolumn{6}{|l|}{ Weather } \\
\hline Temperature, ${ }^{\circ} \mathrm{C}$ & $17.4(8.1)$ & $17.3(8.1)$ & $18.0(7.8)$ & $19.4(7.0)$ & $17.0(8.2)^{\star}$ \\
\hline $\begin{array}{l}\text { Sea-level Pressure, } \\
\mathrm{hPa}\end{array}$ & $1013.5(6.2)$ & $1013.5(6.2)$ & $1013.3(6.3)$ & $1013.2(6.3)$ & $1013.4(6.4)$ \\
\hline Relative Humidity, \% & $62.5(13.1)$ & $62.7(13.1)$ & $61.3(13.0)$ & $63.2(13.7)$ & $60.1(12.4)$ \\
\hline \multicolumn{6}{|l|}{ Air pollution } \\
\hline $\mathrm{PM}_{10}, \mu \mathrm{g} / \mathrm{m}^{3}$ & $41.6(15.5)$ & $41.8(15.6)$ & $40.7(15.1)$ & $37.0(13.5)$ & $43.1(15.7)^{*}$ \\
\hline $\mathrm{PM}_{2.5}, \mu \mathrm{g} / \mathrm{m}^{3}$ & $22.3(7.6)$ & $22.5(7.7)$ & $21.8(7.2)$ & $20.2(6.6)$ & $22.8(7.4)^{\star}$ \\
\hline $\mathrm{PM}_{10-2.5}, \mu \mathrm{g} / \mathrm{m}^{3}$ & $19.3(9.5)$ & $19.4(9.5)$ & $18.9(9.6)$ & $16.7(8.4)$ & $20.4(10.1)^{\star}$ \\
\hline $\mathrm{NO}_{2} \mathrm{ppb}$ & $35.7(7.4)$ & $35.8(7.5)$ & $35.0(7.2)$ & $33.2(6.6)$ & $36.1(7.3)^{\star}$ \\
\hline $\mathrm{O}_{3,} \mathrm{ppb}$ & $30.6(11.2)$ & $30.5(11.3)$ & $31.4(10.9)$ & $31.8(10.2)$ & $31.1(11.4)$ \\
\hline $\mathrm{SO}_{2}, \mathrm{ppb}$ & $3.8(1.5)$ & $3.9(1.5)$ & $3.7(1.4)$ & $3.3(1.2)$ & $3.9(1.4)^{\star}$ \\
\hline $\mathrm{CO} 10 \mathrm{ppm}$ & $5.7(1.7)$ & $5.8(1.7)$ & $5.6(1.6)$ & $5.2(1.5)$ & $5.8(1.6)^{*}$ \\
\hline
\end{tabular}

Abbreviations: $\mathrm{PM}_{10}$ : Particulate Matter of $<10 \mu \mathrm{m}$ in diameter; $\mathrm{PM}_{25}$ : Particulate Matter of $<2.5 \mu \mathrm{m}$ in diameter; IQR: Interquartile Range; $\mathrm{NO}_{2}$ : Nitrogen Dioxide; $\mathrm{SO}$ : Sulfur Dioxide; $\mathrm{O}_{3}$ : Ozone; $\mathrm{CO}$ : Carbon Monoxide; DM: Diabetes Mellitus defined as a self-reported history of doctor-diagnosed disease or glucose $\geq 126 \mathrm{mg} / \mathrm{dL}$ ( $7.0 \mathrm{mmol} / \mathrm{L}$ ). 'Significant difference ( $P$-value $<0.05)$ between non-DM and DM group (marked on total DM) or between uncontrolled and controlled DM group (marked on uncontrolled DM).

Table 2: Descriptive statistics of environmental variables by state of diabetes mellitus (DM). 
Citation: Lim YH, Kim H, Kim JH, Bae S, Park HY, et al. (2014) Benefit of Glycemic Control for Reducing the Effects of Air Pollution on Blood Pressure: A Panel Study. J Diabetes Metab 5: 434 doi:10.4172/2155-6156.1000434

\begin{tabular}{|l|c|c|c|}
\hline \multicolumn{2}{|l|}{ Exposure } & \multicolumn{2}{|c|}{ Change of blood pressure $(\mathbf{m m H g})$} \\
\hline Air pollution & IQR & SBP & DBP \\
\hline $\mathrm{PM}_{10}, \mu \mathrm{gg} / \mathrm{m}^{3}$ & 21.2 & $2.0(0.7,41.7)$ & $2.0(1.2,41.7)$ \\
\hline $\mathrm{PM}_{2.5}, \mu \mathrm{\mu g} / \mathrm{m}^{3}$ & 9.5 & $1.4(0.3,18.9)$ & $1.4(0.8,18.9)$ \\
\hline $\mathrm{PM}_{10-2.5}, \mu \mathrm{\mu g} / \mathrm{m}^{3}$ & 13.6 & $2.5(0.8,26.9)$ & $2.3(1.3,26.9)$ \\
\hline $\mathrm{NO}_{2,} \mathrm{ppb}$ & 9.0 & $1.6(0.4,17.8)$ & $1.7(0.9,17.8)$ \\
\hline $\mathrm{O}_{3,} \mathrm{ppb}$ & 16.4 & $-0.6(-2.9,32.1)$ & $1.0(-0.4,32.2)$ \\
\hline $\mathrm{SO}_{2,} \mathrm{ppb}$ & 1.7 & $2.5(1.1,4.8)$ & $1.3(0.4,4.1)$ \\
\hline $\mathrm{CO}, 10 \mathrm{ppm}$ & 1.6 & $1.4(0.1,4.0)$ & $1.2(0.5,3.9)$ \\
\hline
\end{tabular}

Abbreviations: $\mathrm{PM}_{10}$ : Particulate Matter of $<10 \mu \mathrm{m}$ in diameter; $\mathrm{PM}_{2.5}$ : Particulate Matter of $<2.5 \mu \mathrm{m}$ in diameter; IQR: Interquartile Range; $\mathrm{NO}_{2}$ : Nitrogen Dioxide $\mathrm{SO}_{2}$ : Sulfur Dioxide; $\mathrm{O}_{3}$ : Ozone; $\mathrm{CO}$ : Carbon Monoxide; SBP: Systolic Blood Pressure; DBP: Diastolic Blood Pressure

Models were adjusted for age; sex; exercise level; regular alcohol consumption body mass index; history of hypertension; smoking status, based on cotinine level; education; follow-up time; daily mean temperature; relative humidity; sea-level pressure; and season.

Table 3: Blood pressure changes associated with Interquartile Range (IQR) increases of air pollution concentrations.
CI, 1.3-26.9 mm Hg)) increases than either $\mathrm{PM}_{10}$ or $\mathrm{PM}_{2.5}$. Increases in the levels of most of the gaseous pollutants (e.g., $\mathrm{NO}_{2}, \mathrm{SO}_{2}$, and $\mathrm{CO}$ ) were significantly related to increases in $\mathrm{BP} ; \mathrm{O}_{3}$ was not associated with significant BP changes.

Figure 1 shows the BP changes among the three groups (non-DM, controlled DM, and uncontrolled DM). SBP increases, in uncontrolled DM participants, were associated with most of major air pollutants; 3.8 $\mathrm{mmHg}$ (95\% CI, 0.7-6.9 $\mathrm{mmHg}$ ) per IQR increase in $\mathrm{PM}_{10}, 5.0 \mathrm{mmHg}$ (95\% CI, 1.9-8.0 mmHg) per IQR increase in $\mathrm{PM}_{2.5}, 3.9 \mathrm{mmHg}(95 \%$ CI, $1.0-6.8 \mathrm{mmHg})$ per IQR increase of $\mathrm{NO}_{2}$, and $3.8 \mathrm{mmHg}(95 \% \mathrm{CI}$, $0.5-7.1 \mathrm{mmHg}$ ) per IQR increase of $\mathrm{SO}_{2}$. Non-DM participants also showed significant SBP increases $(1.0-2.5 \mathrm{mmHg}$ ), corresponding to increases in the levels of most of the air pollutants. Unlike uncontrolled DM and non-DM participants, the BPs of controlled DM participants was not significantly associated with air pollutant levels. Among the air pollutants, $\mathrm{PM}_{25}$ showed significant differences in SBP changes between controlled and uncontrolled DM participants at an alpha level of 0.1.

(a)

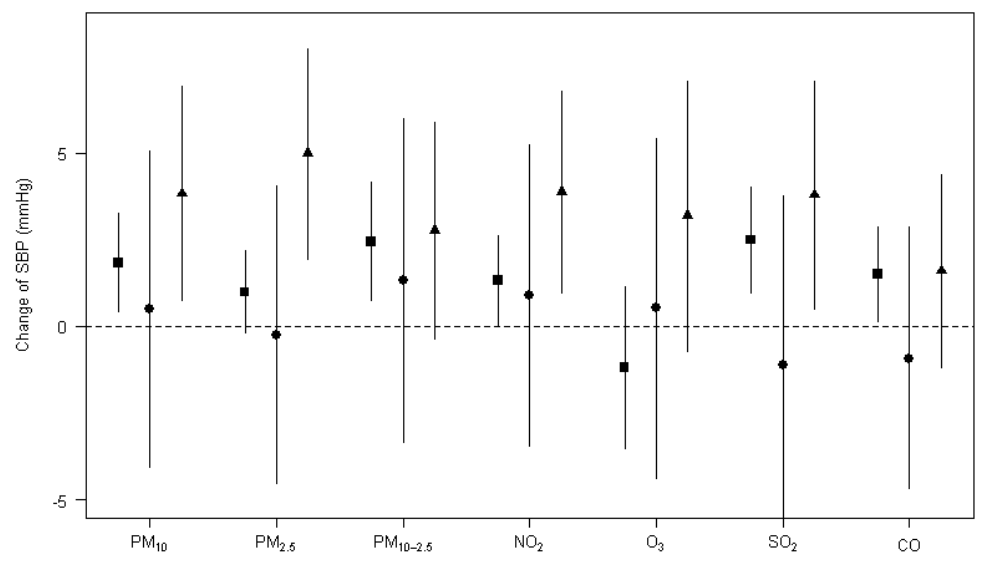

(b)

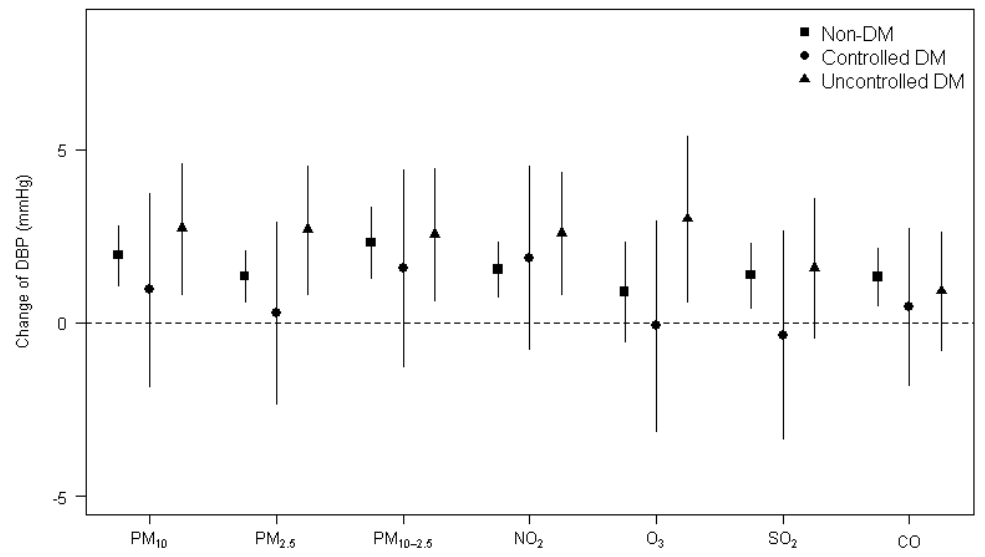

Abbreviations: PM10: Particulate Matter <10 $\mu \mathrm{m}$ in diameter; PM2.5: Particulate Matter<2.5 $\mu \mathrm{m}$ in diameter; IQR: Interquartile Range; $\mathrm{NO}_{2}$ : Nitrogen Dioxide; SO Sulfur Dioxide; $\mathrm{O}_{3}$ : Ozone; CO: Carbon Monoxide; DM: Diabetes Mellitus defined as a self-reported history of doctor-diagnosed disease or glucose $\geq 126 \mathrm{mg} / \mathrm{dL}$ ( 7.0 $\mathrm{mmol} / \mathrm{L})$.

Uncontrolled DM was defined based on glucose level ( $\geq 110 \mathrm{mg} / \mathrm{dL}$ ) among DM; otherwise, controlled DM. Models were adjusted for age; sex; exercise level; regular alcohol consumption; body mass index; history of hypertension; smoking status, based on cotinine level; education; follow-up time; daily mean temperature; relative humidity; sea-level pressure; and season. IQR values for pollutants: PM10 (21.2 $\left.\mu \mathrm{g} / \mathrm{m}^{3}\right), \mathrm{PM} 2.5\left(9.5 \mu \mathrm{g} / \mathrm{m}^{3}\right), \mathrm{PM} 10-2.5\left(13.6 \mu \mathrm{g} / \mathrm{m}^{3}\right), \mathrm{NO}{ }_{2}(9.0 \mathrm{ppb}), \mathrm{O}_{3}(16.4 \mathrm{ppb})$ $\mathrm{SO}_{2}(1.7 \mathrm{ppb})$, and $\mathrm{CO}(0.16 \mathrm{ppm})$.

Figure 1: Blood pressure changes associated with IQR increases in air pollution concentrations among non-DM (squares), controlled DM (circles), and uncontrolled $\mathrm{DM}$ (triangles) participants: (a) systolic blood pressure (SBP, $\mathrm{mmHg}$ ) and (b) diastolic blood pressure (DBP, $\mathrm{mmHg}) \mathrm{changes}$ 
Similarly, DBP changes associated with most air pollutants (except $\mathrm{NO}_{2}$ ) among the non-DM and uncontrolled DM participants were greater than among the controlled DM participants. However, the group differences were not statistically significant at an alpha level of 0.1 .

\section{Discussion}

Air pollutants are known to contribute to cardiovascular disease and deaths, and the effects are more pronounced among individuals with pre-existing conditions, such as DM $[7,8,21]$. However, few studies have investigated whether glycemic control reduces the risk of cardiovascular diseases, such as hypertension, in relation to air pollution exposure. The results of this panel study showed that significant BP changes occurred among non-DM and uncontrolled DM participants when air pollutants increased, whereas BP increases for controlled DM participants were not observed.

Although several studies have found that cardiovascular-related symptoms were exacerbated by increased levels of air pollutants among diabetics compared to non-diabetics, there is a gap in the understanding the benefit of glycemic control for the reduction of cardiovascular disease $[7,8]$. The possible mechanism for the attenuated effects of air pollution on cardiovascular markers, such as BP, among individuals with controlled DM may be explained by a reduction in the oxidative stress and inflammation resulting from the use of diabetes medications. The administration of oral hypoglycemic agents, such as metformin [22], thiazolidinediones [23], and acarbose [24], has been suggested to reduce atherosclerotic vascular disease events by reducing oxidant stress, vascular inflammation, and formation of glycation end products [10]. Hence, the present study's result showing that BP among controlled DM participants was less affected by air pollutants compared to uncontrolled DM participants may be partly explained by these DM treatment effects.

There are a few studies showing the benefits of drug use for protection from the effects of environmental pollutants. Studies have shown that statin use provides a co-benefit for those taking the medication; in addition to its primary effect, patients also demonstrated a lowered inflammatory or oxidative stress response when they were exposed to elevated levels of air pollutants [6]. Jacquemin et al. [25] found that adults with controlled asthma were also less affected by long-term air pollution exposure than uncontrolled asthmatic patients. Following the studies reporting the co-benefits of statins and corticosteroids, this study fills a knowledge gap by describing the benefits of glycemic control on the BP of diabetic individuals in response to air pollutants.

Air pollution concentrations on days when the three diabetes groups (Non-DM, controlled DM, and uncontrolled DM) visited the clinic were distinct. For example, as shown in Table 2, the average air pollution concentrations were greatest on days when participants with uncontrolled DM visited the center, followed by non-DM and controlled DM participants. Since glucose levels, one of the conditions differentiating the controlled vs. uncontrolled DM groups, may be affected by air pollution concentrations, making the results we observed seem reasonable. However, the effects of air pollution on BP were based on BP changes associated with unit increases in air pollution concentrations within the controlled and uncontrolled DM groups [26]. Hence, differences in average air pollution concentrations on the days that controlled and uncontrolled DM participants were tested may not have influenced our findings, based on the assumption of a linear relationship between air pollution exposure and BP.

To the best of our knowledge, this is the first study examining the benefits of DM control on BP affected by exposure to air pollutants in repeated analyses among the elderly. However, this study has some limitations. First, we defined uncontrolled or controlled DM based on each participant's glucose levels and history of doctor-diagnosed DM status at each visit, but we were unable to identify the type of medication they used to control their DM. The benefit of DM control on $\mathrm{BP}$ changes resulting from exposure to air pollutants may differ depending on the medication used for DM control. Although studies have shown that some types of medications (e.g., sulfonylureas) do not provide as much benefit for improving cardiovascular disease as others (e.g., metformin), we could not evaluate differential effects by the type of medications used among DM participants. In addition, we only used fasting glucose measurements as a glycemic level without measuring HbA1C, which was known to be a better index for distinguishing control status of DM $[10,27]$. Second, the magnitude of the glycemic control benefits may vary by age group or race/ethnicity because each population may respond differently to air pollution concentrations. Hence, caution is needed in the generalization of these results to other populations. Third, a higher percentage of DM participants indicated having doctor-diagnosed hypertension than did non-DM participants (62\% of DM vs. $47 \%$ of non-DM participants, Table 1 ). However, there were no significant differences regarding the use of anti-hypertensive medications between the DM and non-DM groups in this study population. Therefore, anti-hypertensive medications may not have been a confounding factor. Fourth, other factors such as life style and salt intake may cause increasing blood pressure in the elderly. To remove the confounding effect, we were able to control for exercise, alcohol, and smoking in the model, but not for salt intake. Because it is not likely that daily salt intake was associated with air pollution levels, the salt intake may not have affected the relationship between air pollution and blood pressure. Lastly, the sample sizes in the controlled and uncontrolled diabetes groups may not have been large enough to test for interactions.

In conclusion, this panel-based study found adverse effects of air pollutants on the BP of participants with uncontrolled DM and those without DM, but did not find significant effects among participants with controlled DM. The effect the size differences between the controlled and uncontrolled DM groups were statistically significant across air pollutants. The study suggests that glycemic control provides benefits for blood pressure changes influenced by air pollutants in the elderly.

\section{Acknowledgements}

The study was partially supported by the Women Scientist Research Program (\#2012R1A1A3005549), and the Global Research Lab (\#K21004000001 10A0500-00710) through the National Research Foundation of Korea (NRF) funded by the Ministry of Education, Science, and Technology.

The study sponsors had no role in study design; collection, analysis, and interpretation of data; writing the report; or the decision to submit the report for publication.

\section{References}

1. Wu S, Deng F, Huang J, Wang H, Shima M, et al. (2013) Blood pressure changes and chemical constituents of particulate air pollution: results from the healthy volunteer natural relocation (HVNR) study. Environ Health Perspect 121: 66-72.

2. Cavallari JM, Eisen EA, Fang SC, Schwartz J, Hauser R, et al. (2008) PM2.5 metal exposures and nocturnal heart rate variability: a panel study of boilermaker construction workers. Environmental health: a global access science source 7: 36

3. Wu S, Deng F, Wei H, Huang J, Wang H, et al. (2012) Chemical constituents of ambient particulate air pollution and biomarkers of inflammation, coagulation and homocysteine in healthy adults: A prospective panel study. Particle and fibre toxicology, 9: 49 . 
Citation: Lim YH, Kim H, Kim JH, Bae S, Park HY, et al. (2014) Benefit of Glycemic Control for Reducing the Effects of Air Pollution on Blood Pressure: A Panel Study. J Diabetes Metab 5: 434 doi:10.4172/2155-6156.1000434

Page 6 of 6

4. Brook RD (2008) Cardiovascular effects of air pollution. Clin Sci (Lond) 115: 175-187.

5. Brook RD, Franklin B, Cascio W, Hong Y, Howard G, et al. (2004) Air Pollution and Cardiovascular Disease: A Statement for Healthcare Professionals From the Expert Panel on Population and Prevention Science of the American Heart Association. Circulation 109:2655-2671.

6. Dubowsky SD, Suh H, Schwartz J, Coull BA, Gold DR (2006) Diabetes, obesity, and hypertension may enhance associations between air pollution and markers of systemic inflammation. Environ Health Perspect 114: 992-998.

7. O'Neill MS, Veves A, Sarnat JA, Zanobetti A, Gold DR, et al. (2007) Air pollution and inflammation in type 2 diabetes: a mechanism for susceptibility. Occup Environ Med 64: 373-379.

8. O'Neill MS, Veves A, Zanobetti A, Sarnat JA, Gold DR, et al. (2005) Diabetes enhances vulnerability to particulate air pollution-associated impairment in vascular reactivity and endothelial function. Circulation 111: 2913-2920.

9. Peel JL, Metzger KB, Klein M, Flanders WD, Mulholland JA, et al. (2007) Ambient air pollution and cardiovascular emergency department visits in potentially sensitive groups. Am J Epidemiol 165: 625-633.

10. Uwaifo GI, Ratner RE (2007) Differential effects of oral hypoglycemic agents on glucose control and cardiovascular risk. Am J Cardiol 99: 51B-67B.

11. Chuang KJ, Yan YH, Chiu SY, Cheng TJ (2011) Long-term air pollution exposure and risk factors for cardiovascular diseases among the elderly in Taiwan. Occup Environ Med 68: 64-68.

12. Delfino RJ, Tjoa T, Gillen DL, Staimer N, Polidori A, et al. (2010) Traffic-related air pollution and blood pressure in elderly subjects with coronary artery disease. Epidemiology 21: 396-404.

13. Jacobs L, Buczynska A, Walgraeve C, Delcloo A, Potgieter-Vermaak S, et al (2012) Acute changes in pulse pressure in relation to constituents of particulate air pollution in elderly persons. Environ Res 117: 60-67.

14. Urch B, Silverman F, Corey P, Brook JR, Lukic KZ, et al. (2005) Acute blood pressure responses in healthy adults during controlled air pollution exposures. Environ Health Perspect 113: 1052-1055.

15. Zanobetti A, Canner MJ, Stone PH, Schwartz J, Sher D, et al. (2004) Ambient pollution and blood pressure in cardiac rehabilitation patients. Circulation 110 2184-2189.

16. Definition and diagnosis of diabetes mellitus and intermediate hyperglycaemia
17. Lim YH, Kim H, Kim JH, Bae S, Park HY, et al. (2012) Air pollution and symptoms of depression in elderly adults. Environ Health Perspect 120: 1023-1028.

18. Rubin DB (1976) Inference and missing data. Biometrika, 63:581-592.

19. Robins JM, Rotnitzky A, Zhao LP (1995) Analysis of semiparametric regression models for repeated outcomes in the presence of missing data. Journal of the American Statistical Association 90:106-121.

20. McCracken J, Baccarelli A, Hoxha M, Dioni L, Melly S, et al. (2010) Annua ambient black carbon associated with shorter telomeres in elderly men: Veterans Affairs Normative Aging Study. Environ Health Perspect 118: 1564 1570.

21. Liu L, Ruddy TD, Dalipaj M, Szyszkowicz M, You H, et al. (2007) Influence of personal exposure to particulate air pollution on cardiovascular physiology and biomarkers of inflammation and oxidative stress in subjects with diabetes. Journal of occupational and environmental medicine / American College of Occupational and Environmental Medicine 49:258-265.

22. UKPDS 28: a randomized trial of efficacy of early addition of metformin in sulfonylurea-treated type 2 diabetes. U.K. Prospective Diabetes Study Group. Diabetes Care 21: 87-92.

23. Bakris G, Viberti G, Weston WM, Heise M, Porter LE, et al. (2003) Rosiglitazone reduces urinary albumin excretion in type II diabetes. J Hum Hypertens 17 7-12.

24. Chiasson JL, Josse RG, Gomis R, Hanefeld M, Karasik A, et al. (2003) Acarbose treatment and the risk of cardiovascular disease and hypertension in patients with impaired glucose tolerance: the STOP-NIDDM trial. JAMA 290: 486-494.

25. Jacquemin B, Kauffmann F, Pin I, Le Moual N, Bousquet J, et al. (2012) Air pollution and asthma control in the Epidemiological study on the Genetics and Environment of Asthma. J Epidemiol Community Health 66: 796-802.

26. Kim JH, Hong YC (2012) GSTM1, GSTT1, and GSTP1 polymorphisms and associations between air pollutants and markers of insulin resistance in elderly Koreans. Environ Health Perspect 120: 1378-1384

27. Perry RC, Shankar RR, Fineberg N, McGill J, Baron AD; Early Diabetes Intervention Program (EDIP) (2001) HbA1c measurement improves the detection of type 2 diabetes in high-risk individuals with nondiagnostic levels of fasting plasma glucose: the Early Diabetes Intervention Program (EDIP). Diabetes Care 24: 465-471 